\title{
Infiltrating lobular carcinoma of the breast: tumor characteristics and clinical outcome
}

\author{
Grazia Arpino ${ }^{1}$, Valerie J Bardou², Gary M Clark¹ and Richard M Elledge ${ }^{1}$
}

${ }^{1}$ Breast Center at Baylor College of Medicine and The Methodist Hospital, Houston, Texas, USA

${ }^{2}$ Paoli Calmettes Institute, Marseille, France

Corresponding author: Richard M Elledge (e-mail: relledge@breastcenter.tmc.edu)

Received: 2 Dec 2003 Accepted: 28 Jan 2004 Published: 17 Feb 2004

Breast Cancer Res 2004, 6:R149-R156 (DOI 10.1186/bcr767)

(C) 2004 Arpino et al., licensee BioMed Central Ltd. This is an Open Access article: verbatim copying and redistribution of this article are permitted in all media for any purpose, provided this notice is preserved along with the article's original URL.

\begin{abstract}
Introduction: Invasive lobular carcinoma (ILC) comprises approximately $10 \%$ of breast cancers and appears to have a distinct biology. Because it is less common than infiltrating ductal carcinoma (IDC), few data have been reported that address the biologic features of ILC in the context of their clinical outcome. In the present study we undertook an extensive comparison of ILC and IDC using a large database to provide a more complete and reliable assessment of their biologic phenotypes and clinical behaviors.

Methods: The clinical and biological features of 4140 patients with ILC were compared with those of 45,169 patients with IDC (not otherwise specified). The median follow-up period was 87 months.

Results: In comparison with IDC, ILC was significantly more likely to occur in older patients, to be larger in size, to be

estrogen and progesterone receptor positive, to have lower S-phase fraction, to be diploid, and to be HER-2, p53, and epidermal growth factor receptor negative. It was more common for ILC than for IDC to metastasize to the gastrointestinal tract and ovary. The incidence of contralateral breast cancer was higher for ILC patients than for IDC patients (20.9\% versus $11.2 \% ; P<0.0001)$. Breast preservation was modestly less frequent in ILC patients than in IDC patients. The 5-year disease-free survival was $85.7 \%$ for ILC and $83.5 \%$ for IDC $(P=0.13)$. The 5 -year overall survival was $85.6 \%$ for ILC and $84.1 \%$ for IDC $(P=0.64)$.

Conclusion: Despite the fact that the biologic phenotype of ILC is quite favorable, these patients do not have better clinical outcomes than do patients with IDC. At present, management decisions should be based on individual patient and tumor biologic characteristics, and not on lobular histology.
\end{abstract}

Keywords: breast cancer, breast carcinoma, infiltrating ductal carcinoma, infiltrating lobular carcinoma, invasive ductal carcinoma of the breast, invasive lobular carcinoma of the breast, special type of breast cancer

\section{Introduction}

Carcinoma of the breast is a histologically heterogeneous disease. Invasive lobular carcinoma (ILC) accounts for $8-14 \%$ of all breast cancers [1,2]. Data from a recent epidemiologic study [3] indicate that for unknown causes the incidence of this type of breast cancer is increasing, especially among postmenopausal women.

The morphologic features of lobular carcinoma differ from those of ductal carcinoma. ILC is characterized by small, round cells that are bland in appearance and have scant cytoplasm, which infiltrate the stroma in single file and sur- round benign breast tissues in a targeted manner $[1,4]$. Infiltration typically does not destroy anatomic structures or incite a substantial connective tissue response. By virtue of their distinctive growth pattern and biology, lobular carcinomas often fail to form distinct masses that can easily be diagnosed by palpation or mammography. This can make early diagnosis challenging $[5,6]$ and breast conservation approaches more difficult. Lobular carcinomas may have a substantially increased propensity for multifocal and multicentric distribution and for bilaterality [5,7-11]. Metastatic spread with an uncommon pattern of involvement has been reported [12,13].

$\mathrm{CNS}=$ central nervous system; DFS $=$ disease-free survival; EGFR $=$ epidermal growth factor receptor; ER $=$ estrogen receptor; IDC $=$ infiltrating ductal carcinoma; ILC = infiltrating lobular carcinoma; $\mathrm{OS}=$ overall survival; $\mathrm{PgR}=$ progesterone receptor. 
Because it is substantially less common than infiltrating ductal carcinoma (IDC), knowledge about the clinical outcome of lobular carcinoma has been based on studies including relatively small numbers of patients. Reported prognosis varies and has been reported to be worse $[14,15]$, no different [16-19], or better [20] than that with IDC. This reported variability might be due to relatively small numbers of cases in each analysis. In addition, few data have been reported on the biologic features of lobular carcinomas within the context of their clinical outcome. We therefore undertook an extensive comparison of ILC and IDC using a large database to provide a more complete and reliable assessment of their biologic phenotypes and clinical behaviors, which might yield information useful for clinical decision making or for further exploring the biologic nature of this disease.

\section{Methods \\ Study population}

The Breast Center at Baylor College of Medicine maintains databases of breast cancer patients whose biopsy or mastectomy specimens were sent to central laboratories for steroid receptor assays. These patients were diagnosed and treated at more than 370 academic and community institutions throughout the USA. The central laboratories were located at the University of Texas Health Science Center at San Antonio and at Nichols Institute in San Juan Capistrano, California. Histologic diagnoses were made by pathologists at community hospitals and were not reviewed centrally. ILC was not further subtyped in these databases, and patients with mixed ILC and IDC were excluded. Follow-up information was obtained from tumor registries, by direct review of medical records conducted by data managers, or by data collection forms completed at the office of the referring physicians. These databases contain information on 50,399 patients with early breast cancer who were diagnosed between 1970 and 1998. Among them, $4140(8.2 \%)$ were diagnosed as having ILC and 45,169 $(89.6 \%)$ as having IDC. Patients with special histologic types (tubular, mucinous, and medullary) were excluded, as were those with gross distant metastases at diagnosis. Histologic grade was not analyzed in the present study because in most cases this information was not available.

The patient information contained in this report was obtained from two data repositories maintained by the Breast Center at Baylor College of Medicine. Each repository has been reviewed by Institutional Review Boards at the University of Texas Health Science Center at San Antonio and at Baylor College of Medicine.

\section{Prognostic factors}

Estrogen receptor (ER) levels were measured using the dextran-coated charcoal method as previously described [21]. From 1970 to $1984,\left[{ }^{3} \mathrm{H}\right]$ estradiol was used as a receptor $(\mathrm{PgR})$ levels were measured by sucrose density gradient [22]. In 1985, the standard multipoint dextrancoated charcoal assay was modified to incorporate $\left[{ }^{125} \mathrm{I}\right]$ estradiol and $\left[{ }^{3} \mathrm{H}\right] \mathrm{R} 5020$ in a single assay, allowing simultaneous determination of levels of both ER and PgR [23]. Levels of $3 \mathrm{fmol} / \mathrm{mg}$ protein or greater were considered positive for ER, and levels of $5 \mathrm{fmol} / \mathrm{mg}$ protein or greater were considered positive for PgR. DNA ploidy and S-phase fraction were evaluated using flow cytometry, as previously described [24-26]. S-phase fractions below $6 \%$ were considered low, those in the range $6-10 \%$ were considered intermediate, and those in excess of $10 \%$ were considered high. HER-2 status was determined using Western blotting [27]. The cutoff value between low and high HER-2 expression was $1 \mathrm{U} / \mu \mathrm{g}$ protein. Epidermal growth factor receptor (EGFR) levels were measured by radiobinding assay, using fixed concentrations of radiolabeled EGF and varying concentrations of unlabeled EGF. Levels of $10 \mathrm{fmol} / \mathrm{mg}$ or greater were considered positive. This cutoff has been in use at the Nichols Institute since 1992 and its use is in accordance with published studies $[28,29]$. p53 status was determined by immunohistochemistry, and negative nuclear staining was a surrogate marker for normal p53 [30].

\section{Statistical methods}

Descriptive statistics are reported as frequencies or medians. The clinical and biologic characteristics of lobular and ductal carcinoma were compared using contingency tables, $\chi^{2}$ tests and Fisher's exact tests.

Overall survival (OS) was defined as the interval between the diagnostic biopsy and death from any cause, death being scored as an event, and patients who were still alive were censored at the time of last follow-up. OS after first recurrence was calculated from the date of first recurrence, death being scored as an event, and patients who were still alive were censored at the time of last follow-up. Disease-free survival (DFS) was also calculated from the date of first diagnostic biopsy, with first recurrences, local or distant, being scored as an event, and with censoring of other patients at the time of last follow-up or death. Local recurrence was defined as tumor arising in the treated breast, chest wall or axilla. OS and DFS curves were drawn using Kaplan-Meier estimates, and were compared using log rank tests. Survival rates are presented with their $95 \%$ confidence intervals.

Multivariate analyses of DFS and OS, with stepwise variables selection, were conducted using Cox proportional hazard regression models. Analyses were performed using SAS Version 8.00 (SAS Institute Inc., Cary, NC, USA).

\section{Results}

\section{Patient and tumor characteristics}

From a total of 50,399 patients with early breast cancer in the Baylor College of Medicine Breast Cancer data- 
bases, we identified 4140 patients (8.2\%) with ILC and 45,169 (89.6\%) patients with IDC (not otherwise specified). The median follow-up time was 87 months (range 0-254 months).

Table 1 summarizes the clinical and biologic tumor characteristics according to histologic type. The median ages of patients with ILC and IDC were 64.6 and 60.6 years, respectively. ILCs were slightly larger on average $(53.8 \%$ larger than $2 \mathrm{~cm})$ than IDCs $(48.6 \%$ larger than $2 \mathrm{~cm}$; $P<0.0001)$. More revealing, however, was a $50 \%$ greater chance of ILC presenting as a large tumor, with $14.0 \%$ of ILCs exceeding $5 \mathrm{~cm}$ as compared with $9.1 \%$ of IDCs. Despite this difference in tumor size, there was no difference in the frequency of axillary node involvement.

Despite the larger tumor size, ILCs had more favorable biologic characteristics (Table 1). The proportion of ERpositive tumors was $92.7 \%$ for ILC and $81.2 \%$ for IDC $(P<0.0001)$. PgR was expressed in $67.4 \%$ of ILCs and in $60.2 \%$ of IDCs $(P<0.0001)$. Compared with IDCs, ILCs were much more likely to be diploid $(69.8 \%$ of ILCs versus $43.6 \%$ of IDCs; $P<0.0001)$, have a low or intermediate S-phase fraction $(87.8 \%$ of ILCs versus $68.6 \%$ of IDCs; $P<0.0001)$, have normal p53 status $(74.4 \%$ of ILCs versus $46.5 \%$ of IDCs; $P<0.0001$ ), and be negative for EGFR $(94.1 \%$ of ILCs versus $80.7 \%$ of IDCs; $P<0.0001)$ and HER-2 (89.34\% of ILCs versus $75.6 \%$ of IDCs; $P<0.0001)$. Thus, in comparison with IDC, ILC was more likely to occur in older patients, to be larger in size, to be ER and PgR positive, to have a lower S-phase fraction, to be diploid, and to be negative for HER-2, p53 and EGFR.

The pattern of metastatic dissemination in ILC and IDC was also different (Table 2). Lung and pleura involvement was more frequently observed with IDCs $(P=0.0019)$, as was involvement of distant nodes $(P=0.018)$ and of the central nervous system (CNS; $P=0.0032$ ). The detail of coding in the database was not sufficient to permit further distinction between brain, spinal cord, and meningeal metastases, and therefore the incidence of leptomeningeal disease could not be determined. ILC was three times more likely to metastasize to the peritoneum, gastrointestinal tract, and ovaries (6.7\% versus $1.8 \%)$. Information on contralateral breast tumors was also available on the subset of 2855 patients in whom sites of breast cancer distant from the primary could be assessed. Contralateral breast cancers in this group were more frequent among those with ILC $(20.9 \%)$ than among those with IDC (11.2\%; $P<0.0001$; data not shown).

Both local and systemic therapy for breast cancer differed according to histologic type (Table 3 ). Patients with ILC were slightly less likely to undergo lumpectomy $(9.5 \%$ of patients with ILC versus $12.7 \%$ of patients with IDC;
Table 1

Patients and tumor biological characteristics by histologic group

\begin{tabular}{|c|c|c|c|}
\hline & ILC & IDC & $P$ \\
\hline Patients $(n)$ & 4140 & 45169 & \\
\hline $\begin{array}{l}\text { Tumor size } \\
\text { Number with data } \\
\leq 2 \mathrm{~cm}(\%) \\
>2 \text { and } \leq 5 \mathrm{~cm}(\%) \\
>5 \mathrm{~cm}(\%)\end{array}$ & $\begin{array}{l}3962 \\
46.1 \\
39.8 \\
14.0\end{array}$ & $\begin{array}{c}43827 \\
51.3 \\
39.5 \\
9.1\end{array}$ & $<0.0001$ \\
\hline $\begin{array}{l}\text { Age } \\
\begin{array}{l}\text { Number with data } \\
\leq 50 \text { years } \\
>50 \text { years }\end{array}\end{array}$ & $\begin{array}{r}3501 \\
19.4 \\
80.6\end{array}$ & $\begin{array}{c}38436 \\
27.8 \\
72.2\end{array}$ & $<0.0001$ \\
\hline $\begin{array}{l}\text { Positive lymph nodes } \\
\text { Number with data } \\
0 \\
\geq 1\end{array}$ & $\begin{array}{l}3891 \\
57.3 \\
42.7\end{array}$ & $\begin{array}{c}43066 \\
58.0 \\
42.0\end{array}$ & NS \\
\hline $\begin{array}{l}\text { Estrogen receptor } \\
\text { Number tested } \\
\text { Positive (\%) }\end{array}$ & $\begin{array}{c}4140 \\
92.7\end{array}$ & $\begin{array}{c}45169 \\
81.2\end{array}$ & $<0.0001$ \\
\hline $\begin{array}{l}\text { Progesterone receptor } \\
\text { Number tested } \\
\text { Positive (\%) }\end{array}$ & $\begin{array}{c}4075 \\
67.4\end{array}$ & $\begin{array}{c}44307 \\
60.2\end{array}$ & $<0.0001$ \\
\hline $\begin{array}{l}\text { Ploidy } \\
\text { Number tested } \\
\text { Diploid (\%) }\end{array}$ & $\begin{array}{c}3763 \\
69.8\end{array}$ & $\begin{array}{c}40123 \\
43.6\end{array}$ & $<0.0001$ \\
\hline $\begin{array}{l}\text { S-phase fraction } \\
\text { Number tested } \\
\text { Low } \\
\text { Intermediate } \\
\text { High }\end{array}$ & $\begin{array}{l}3339 \\
68.6 \\
19.2 \\
12.2\end{array}$ & $\begin{array}{l}34620 \\
46.7 \\
21.9 \\
31.4\end{array}$ & $<0.0001$ \\
\hline $\begin{array}{l}\text { p53 } \\
\text { Number tested } \\
\text { Negative (normal; \%) }\end{array}$ & $\begin{array}{c}86 \\
74.4\end{array}$ & $\begin{array}{c}1009 \\
46.5\end{array}$ & $<0.0001$ \\
\hline $\begin{array}{l}\text { HER-2 } \\
\text { Number tested } \\
\text { Negative (\%) }\end{array}$ & $\begin{array}{l}263 \\
89.3\end{array}$ & $\begin{array}{c}2909 \\
75.6\end{array}$ & $<0.0001$ \\
\hline $\begin{array}{l}\text { Epidermal growth factor re } \\
\text { Number tested } \\
\text { Negative }(\%)\end{array}$ & $\begin{array}{l}203 \\
94.1\end{array}$ & $\begin{array}{c}2366 \\
80.7\end{array}$ & $<0.0001$ \\
\hline
\end{tabular}

IDC, invasive ductal carcinoma; ILC, invasive lobular carcinoma.

$P<0.0001)$. Probably because of the higher hormone receptor content, adjuvant endocrine therapy was more frequently given to patients with ILC (28.8\%) than to those with IDC $(22.9 \% ; P<0.0001)$. On the other hand, the number of patients with ILC who received adjuvant chemotherapy was significantly lower $(16.2 \%$ in ILC patients versus $23.7 \%$ in IDC patients; $P<0.0001$ ).

\section{Disease-free and overall survival}

A trend toward better DFS was observed for ILC patients. The 5 -year DFS was $85.7 \%$ for patients with ILC and $83.5 \%$ for those with IDC $(P=0.13)$. This modest difference is not clinically or biologically significant. However, 
Table 2

\begin{tabular}{lccc}
\multicolumn{4}{l}{ Distant sites of first recurrence } \\
\hline Sites & $\begin{array}{c}\text { ILC } \\
(n=179 ; \%)\end{array}$ & $\begin{array}{c}\text { IDC } \\
(n=2576 ; \%)\end{array}$ & $P$ \\
\hline Lungs/pleura & 9.0 & 17.6 & 0.0019 \\
CNS & 1.7 & 5.3 & 0.032 \\
Ovary & 2.2 & 0.7 & 0.0003 \\
Gastrointestinal tract ${ }^{\mathrm{a}}$ & 4.5 & 1.1 & 0.009 \\
Nodes & 15.5 & 22.0 & 0.018 \\
Bone & 34.6 & 35.5 & $\mathrm{NS}$ \\
Skin & \\
Liver & 31.8 & 27.3 & $\mathrm{NS}$ \\
Pituitary & 7.3 & 10.9 & $\mathrm{NS}$ \\
\hline
\end{tabular}

Percentages do not add up to $100 \%$ because of multiple metastatic sites in the same patient and infrequent or unknown sites not shown. aStomach, small bowel, colon, appendix, duodenum, and peritoneum. bSoft tissue and skin.

CNS, central nervous system; IDC, invasive ductal carcinoma; ILC, invasive lobular carcinoma; NS, not significant.

although ILC patients experienced recurrence less frequently than did IDC patients during the first few years after diagnosis, the two DFS curves converged after longer follow-up (Fig. 1a). Despite having more favorable biologic characteristics, the 5 -year OS was not better for ILC (85.6\%) than for IDC (84.1\%; $P=0.64$; Fig. 1b). For node-negative patients, DFS and OS were very similar for the two histologic types.

The median survival after the first recurrence was slightly longer for ILC patients (22 months, range 0-115 months)
Table 3

Local and systemic adjuvant therapy by histologic type

\begin{tabular}{|c|c|c|c|}
\hline \multirow[b]{2}{*}{ Therapy } & \multicolumn{2}{|c|}{ Histologic type } & \multirow[b]{2}{*}{$P$} \\
\hline & ILC & IDC & \\
\hline \multicolumn{4}{|l|}{ Surgery } \\
\hline Number of patients & 4197 & 45995 & \\
\hline None $(\%)$ & 1.1 & 0.8 & \\
\hline Modified radical mastectomy (\%) & 89.4 & 86.5 & $<0.0001$ \\
\hline Lumpectomy (\%) & 9.5 & 12.7 & \\
\hline \multicolumn{4}{|l|}{ Adjuvant therapy } \\
\hline Number of patients & 2817 & 31043 & \\
\hline None $(\%)$ & 42.4 & 42.3 & \\
\hline Chemotherapy (\%) & 16.2 & 23.7 & \\
\hline Endocrine therapy (\%) & 28.8 & 22.9 & $<0.0001$ \\
\hline $\begin{array}{l}\text { Chemotherapy and endocrine } \\
\text { therapy (\%) }\end{array}$ & 12.6 & 11.1 & \\
\hline
\end{tabular}

IDC, invasive ductal carcinoma; ILC, invasive lobular carcinoma.

than for IDC patients (19 months, range 0-119 months; $P=0.002$ ), and the 5-year survival after the first recurrence was $32.8 \%$ for patients with ILC as compared with $26.7 \%$ for patients with IDC (Fig. 2).

\section{Multivariate analyses}

Multivariate analyses were performed using Cox regression models to determine whether ILC was an independent prognostic factor for recurrence and death (Table 4). Factors included in these analyses were tumor size, number of involved nodes, age, ER status, PgR status, DNA ploidy, S-phase, and histologic type. Data were available for all of these variables in 33,860 patients. From these variables, the factors that remained independently associated with recurrence, as well as with survival, were

\section{Figure 1}
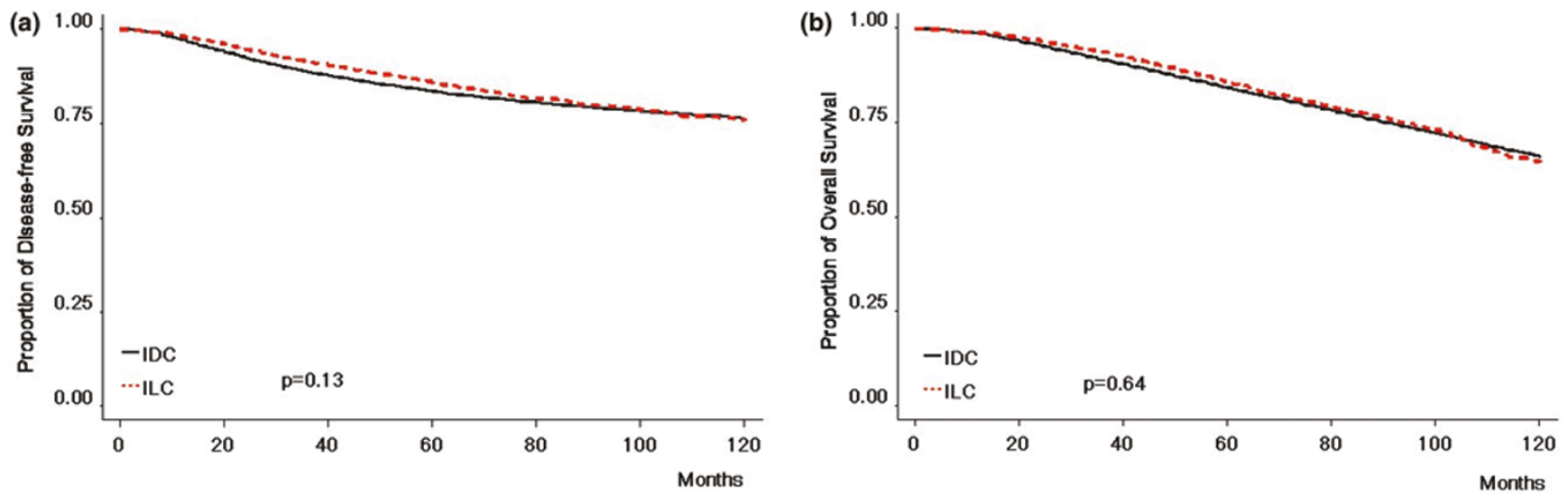

(a) The 5-year disease-free survival (DFS) was $85.7 \%$ (95\% confidence interval [Cl] 84.4-87.1\%) for invasive lobular carcinoma (ILC) versus 83.5\% (95\% Cl 83.1-84.0\%) for invasive ductal carcinoma (IDC; $P=0.13$ ). (b) The 5-year overall survival (OS) was $85.6 \%(95 \% \mathrm{Cl}$ $84.2-87.0 \%)$ for ILC and $84.1 \%(95 \% \mathrm{Cl} 83.7-84.6 \%)$ for IDC $(P=0.64)$. 
Table 4

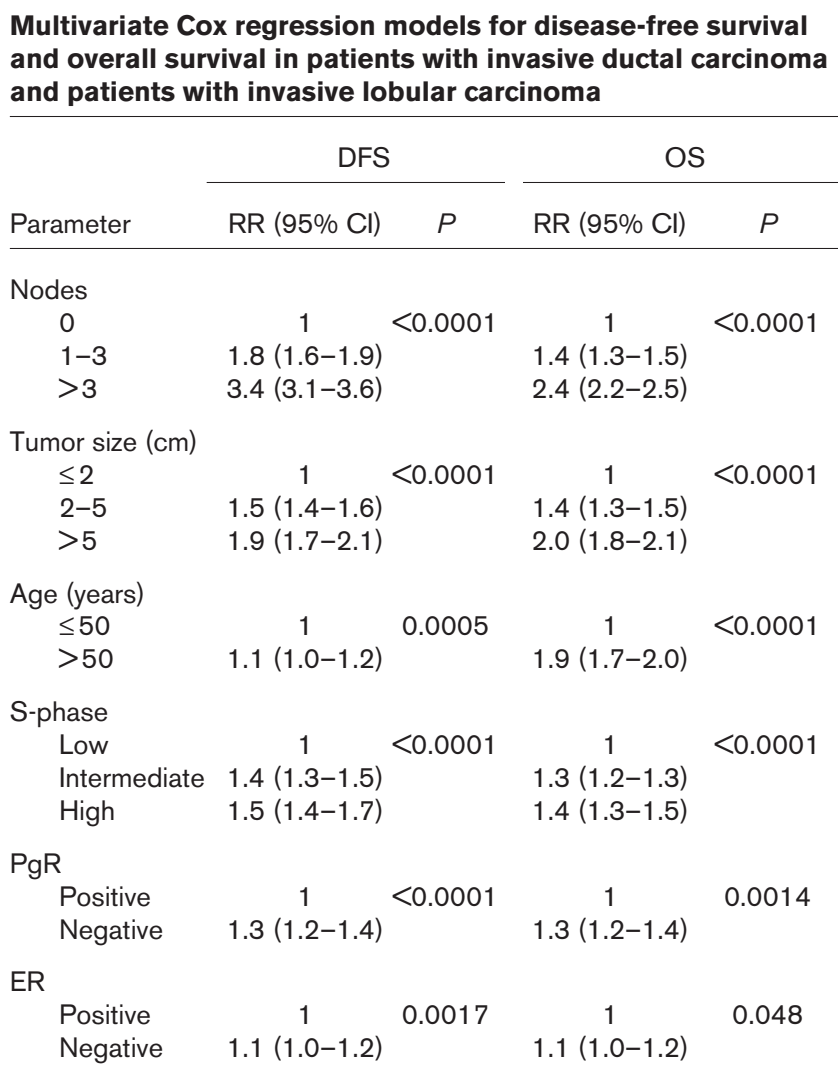

$\mathrm{Cl}$, confidence interval; DFS, disease-free survival; ER, estrogen receptor; OS, overall survival; $\mathrm{PgR}$, progesterone receptor; $\mathrm{RR}$, relative risk.

as follows: lymph node status, tumor size, age, S-phase, $\mathrm{PgR}$ status, and ER status. Once adjustment based on these six parameters was made, histologic type did not emerge as an important prognostic factor. Thus, the lack of prognostic significance related to ILC versus IDC in univariate analyses is confirmed by the results of the multivariate analyses.

In addition, to determine whether traditional prognostic factors for IDC would be of value in patients with ILC, a second set of multivariate analyses of DFS and OS were performed only in patients with ILC (Table 5). For DFS, lymph node status, tumor size, S-phase, PgR status, and DNA ploidy retained their independent prognostic value. For OS, nodal status, age, tumor size, ER status, and Sphase were independent prognostic factors.

\section{Discussion}

The present study demonstrates that ILC has distinctive clinical and biologic characteristics compared with IDC. Lobular carcinomas were more likely to occur in older patients; to be larger in size, ER and PgR positive, and diploid with a low S-phase fraction; and to have normal p53 status and low to absent EGFR and HER-2. The dis-
Table 5

Multivariate Cox regression models for disease-free survival and overall survival in invasive lobular carcinoma patients

\begin{tabular}{|c|c|c|c|c|}
\hline \multirow[b]{2}{*}{ Parameter } & \multicolumn{2}{|l|}{ DFS } & \multicolumn{2}{|c|}{ os } \\
\hline & RR (95\% Cl) & $P$ & RR (95\% Cl) & $P$ \\
\hline \multicolumn{5}{|l|}{ Nodes } \\
\hline 0 & 1 & $<0.0001$ & 1 & $<0.0001$ \\
\hline $1-3$ & $2.2(1.6-3.2)$ & & $1.4(1.1-1.9)$ & \\
\hline$>3$ & $4.1(2.9-5.7)$ & & $2.2(1.7-2.9)$ & \\
\hline \multicolumn{5}{|l|}{ Tumor size $(\mathrm{cm})$} \\
\hline$\leq 2$ & 1 & $<0.0001$ & 1 & $<0.0001$ \\
\hline$>2$ & $1.9(1.4-2.6)$ & & $1.6(1.3-2.1)$ & \\
\hline \multicolumn{5}{|l|}{ Age (years) } \\
\hline$\leq 50$ & - & NS & 1 & $<0.0001$ \\
\hline$>50$ & - & & $2.3(1.7-3.1)$ & \\
\hline \multicolumn{5}{|l|}{ S-phase } \\
\hline Low & 1 & 0.002 & 1 & $<0.0293$ \\
\hline $\begin{array}{l}\text { Intermediate } \\
\text {-high }\end{array}$ & $1.7(1.3-2.2)$ & & $1.3(1.0-1.6)$ & \\
\hline \multicolumn{5}{|l|}{$\mathrm{PgR}$} \\
\hline Positive & 1 & 0.003 & - & NS \\
\hline Negative & $1.5(1.1-1.9)$ & & - & \\
\hline \multicolumn{5}{|l|}{ ER } \\
\hline Positive & - & NS & 1 & 0.0006 \\
\hline Negative & - & & $1.9(1.3-2.8)$ & \\
\hline \multicolumn{5}{|l|}{ Ploidy } \\
\hline Diploid & 1 & 0.03 & - & NS \\
\hline Aneuploid & $1.7(1.3-2.2)$ & & - & \\
\hline
\end{tabular}

$\mathrm{Cl}$, confidence interval; DFS, disease-free survival; ER, estrogen receptor; NS, not significant; OS, overall survival; PgR, progesterone receptor; $\mathrm{RR}$, relative risk.

\section{Figure 2}

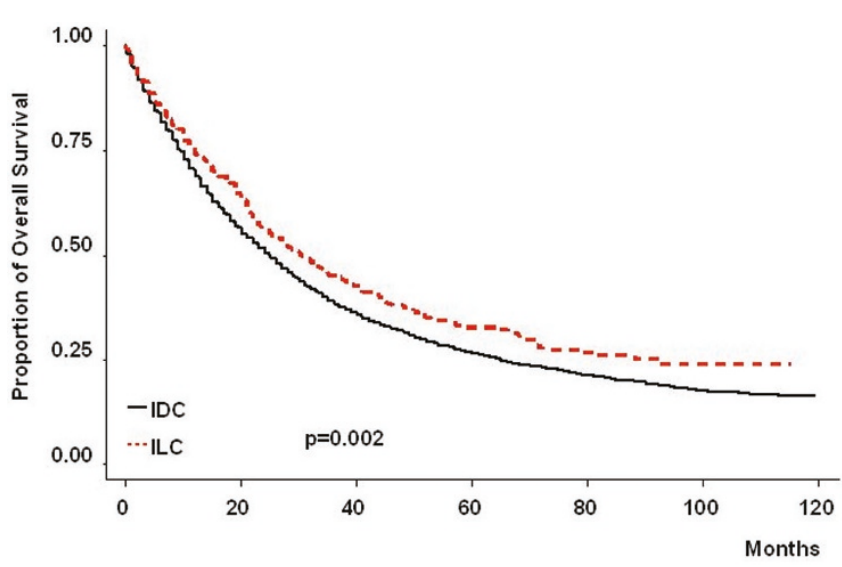

The 5-year overall survival (OS) after the first recurrence was 32.8\% (95\% confidence interval [Cl] 28.0-37.6\%) for invasive lobular carcinoma (ILC) and $26.7 \%(95 \% \mathrm{Cl} 25.3-28.0)$ for invasive ductal carcinoma (IDC). The median survival after first recurrence was 22 months (range $0-115$ months) for ILC versus 19 months (range $0-119$ months) for IDC ( $P=0.002)$. 
tributions of metastases were also different. Despite a substantially less aggressive biologic phenotype, recurrence and survival were very similar between ILC and IDC patients.

To our knowledge this is the largest published report on ILC that comprehensively evaluates biologic characteristics and clinical outcomes. The incidence of ILC observed in the present study (8.2\%) is in accordance with the incidence range of $8-14 \%$ reported in the literature $[1,14,31-33]$. In addition, the large number of patients, the multi-institutional nature of the study population, and the median follow-up period of more than 7 years strengthen the reliability of the results and permit extrapolation of the findings to routine clinical practice.

Clinical characteristics at diagnosis are different for ILC than for IDC. Several studies showed that patients with ILC are on average older at presentation than are IDC patients $[18,19,34]$. Consistent with these data, in the present study the median ages at diagnosis were 64.6 years for patients with ILC and 60.6 years for patients with IDC. This older age at diagnosis in those with ILC could be due to a low proliferative rate or greater difficulties in detecting ILC. In terms of tumor size, $14 \%$ of ILCs were found to exceed $5 \mathrm{~cm}$ as compared with only $9.1 \%$ of IDCs. The lack of a desmoplastic reaction may make the lesion impalpable and invisible, both clinically and mammographically, deferring the identification and probably explaining why lobular carcinomas were larger at diagnosis than IDCs. However, despite the slightly larger size of ILCs, the rate of lymph node involvement was the same in each group. The uniform appearance of bland tumor cells that lack cellular atypia and often have a low mitotic rate make the lobular carcinoma cells more difficult to detect in metastatic lymph nodes. Thus, particular attention should be given to histologic examination of axillary nodes in resection specimens of lobular carcinomas because nodal metastases are more often missed with ILCs, and false-negative results are more frequently reported compared with ductal carcinomas [35].

From this report it is evident that the metastatic pattern for ILC differs from that of IDC. ILC was less likely to affect the lungs, pleura, and CNS than was IDC. By contrast, the peritoneum, ovary, and gastrointestinal system were much more likely to be involved in advanced ILC. Entries for gastrointestinal involvement in the database represent peritoneal and parenchymal involvement. CNS metastases were more common with IDC. This database could not clearly distinguish between brain, spinal cord, or leptomeningeal metastases in its classification of CNS involvement. It has been reported that ILC more often involves the meninges and spinal fluid $[13,36-38]$ but we were unable to address this issue directly because of limi- distinct metastatic pattern are unclear. The difference could be due to a cell size or shape with physical properties that favor certain areas with microanatomy that is more conducive to stopping or trapping these types of cells. Alternatively, the microenvironment of the ovary or peritoneum may provide growth and survival factors that favor ILC cells over IDC cells. Additional molecular or biologic differences might account for this peculiar pattern of metastasis. It has been demonstrated that loss of expression of the cell-cell adhesion molecule E-cadherin in ILC may decrease adhesiveness of cells and facilitate this type of infiltration $[19,39,40]$. Indeed, the findings of this study support a different molecular biology of ILC.

Bilateral involvement is reported to be $20-29 \%$ in lobular carcinoma $[10,12,16,41,42]$. In our dataset the incidence of contralateral breast cancer in women with ILC was nearly double that in women with IDC. This finding could make a compelling case for the use of tamoxifen to prevent contralateral breast cancer in women with lobular primaries.

Because only a few small and scattered studies have addressed the biologic features of ILC, one of the main objectives of the present study was to characterize more comprehensively its biologic phenotype. This report definitively confirms and extends the findings of some previous studies $[11,12,17,43-45]$ indicating that lobular carcinomas are significantly more likely to be steroid receptor positive than are IDCs. These results also demonstrate that lobular carcinomas are more likely to have low S-phase fractions and to be diploid. The evaluation of S-phase fractions in ILC in other published series confirms our findings $[18,20,46]$. Few reports have evaluated the well studied growth factor receptors HER-2 and EGFR, or the tumor suppressor gene p53 in ILC. In the present analysis, no more than $5-10 \%$ of tumors classified by a broad range of pathologists as ILC over-expressed EGFR and/or HER-2. Positivity for p53 was found half as often in ILC as in IDC. Only two small studies have analyzed these molecules in ILC [47-49] and their results are similar to those reported here. The $5-10 \%$ of patients who were positive for HER-2 or EGFR, or who were p53 positive, may not have been of the classic ILC subtype but possibly a variant, such as those found in the pleomorphic or mixed ILC-IDC categories. ILC subtypes have been reported to have different biologic characteristics and clinical behavior as compared with the classic subtype [50-52], but the difference has not found to be statistically significant, although the number of patients included in the various studies is small. Unfortunately, we were unable to subtype further those tumors with lobular histology. More study is needed on these specific subtypes. However, together these findings suggest that ILC is biologically different from IDC.

In general, the management of patients in this study with ILC was somewhat different from the management of 
patients with IDC. In practice, the histologic type appears to play a role in the choice of surgical procedure selected $[11,44,53,54]$. This analysis suggested that ILC was treated by mastectomy slightly more frequently than was IDC. Although this tendency to favor mastectomy may be related to factors specific to the patient and/or surgeon, the choice for these procedures is also influenced by pathologic findings. Indeed, the diminished fibrotic reaction present in ILC makes it difficult for pathologists and surgeons to determine the gross extent of the disease during surgery, and to achieve tumor-free margins after a limited excision. With respect to systemic therapy, because lobular carcinomas are more frequently steroid receptor positive tumors, as expected a greater proportion of ILC patients than of IDC patients received adjuvant endocrine therapy.

From previous studies the prognosis for ILC compared to IDC is unclear. An important finding of the present large study is that the 5-year OS of patients with ILC is not different from that of patients with IDC. Therefore, the fact that ILC has more favorable prognostic factors does not translate into a survival advantage for patients with ILC. Although ILC is associated with a less aggressive phenotype, this is offset by lobular carcinoma being more difficult to detect early, either by clinical examination or mammography. Furthermore, the reported higher rate of false-negative lymph nodes by histologic examination in lobular carcinomas could cause a general under-staging of this histologic type at the time of surgery.

Multivariate analyses did not identify any prognostic differences associated with ILC or IDC. In these analyses, considering all ILC and IDC patients together, lymph nodes status, tumor size, age, S-phase, PgR status, and ER status were found to be associated with both recurrence and survival, but histology was not an important independent predictor of recurrence or survival. Furthermore, the same standard prognostic factors (tumor size, axillary nodal status, hormone receptors, S-phase, and age) used in ductal carcinoma are applicable in lobular carcinoma as well [55].

\section{Conclusion}

Results from this large dataset show clearly that ILC and IDC are different entities with different clinical courses and different biologic phenotypes, but no clinically meaningful differences in survival are evident. At present, both types of breast cancer should be managed similarly and histologic subtype (lobular or ductal) should not be a factor in the therapeutic decision-making process, and should not be considered an important prognostic or predictive factor at diagnosis. Emerging technologies such as high throughput genome mapping and microchip cDNA expression arrays may further elucidate molecular differences in these different types of breast cancer.

\section{Competing interests}

None declared.

\section{Acknowledgements}

Supported in part by NIH grants P01 CA30195 and P50 CA58183 (SPORE) and FIRC (Fondazione Itaiana Ricarca sul Cancro) grant. We thank Gary Chamness and Carole Elledge for review of the manuscript.

\section{References}

1. Martinez V, Azzopardi JG: Invasive lobular carcinoma of the breast: incidence and variants. Histopathology 1979, 3:467488.

2. Borst MJ, Ingold JA: Metastatic patterns of invasive lobular versus invasive ductal carcinoma of the breast. Surgery 1993, 114:637-641; discussion 641-632.

3. $\mathrm{Li} \mathrm{Cl,} \mathrm{Anderson} \mathrm{BO,} \mathrm{Porter} \mathrm{P,} \mathrm{Holt} \mathrm{SK,} \mathrm{Daling} \mathrm{JR,} \mathrm{Moe} \mathrm{RE:}$ Changing incidence rate of invasive lobular breast carcinoma among older women. Cancer 2000, 88:2561-2569.

4. Fisher ER, Gregorio RM, Fisher B, Redmond C, Vellios F Sommers SC: The pathology of invasive breast cancer. A syllabus derived from findings of the National Surgical Adjuvant Breast Project (protocol no. 4). Cancer 1975, 36:1-85.

5. Krecke KN, Gisvold JJ: Invasive lobular carcinoma of the breast: mammographic findings and extent of disease at diagnosis in 184 patients. AJR $A m J$ Roentgenol 1993, 161: 957-960.

6. Yeatman TJ, Cantor AB, Smith TJ, Smith SK, Reintgen DS, Miller MS, Ku NN, Baekey PA, Cox CE: Tumor biology of infiltrating lobular carcinoma. Implications for management. Ann Surg 1995, 222:549-559; discussion 559-561.

7. Cornford EJ, Wilson AR, Athanassiou E, Galea M, Ellis IO, Elston CW, Blamey RW: Mammographic features of invasive lobular and invasive ductal carcinoma of the breast: a comparative analysis. Br J Radiol 1995, 68:450-453.

8. Helvie MA, Paramagul $C$, Oberman HA, Adler DD: Invasive lobular carcinoma. Imaging features and clinical detection. Invest Radiol 1993, 28:202-207.

9. Newstead GM, Baute PB, Toth HK: Invasive lobular and ductal carcinoma: mammographic findings and stage at diagnosis. Radiology 1992, 184:623-627.

10. Dixon JM, Anderson TJ, Page DL, Lee D, Duffy SW, Stewart HJ: Infiltrating lobular carcinoma of the breast: an evaluation of the incidence and consequence of bilateral disease. $\mathrm{Br} J$ Surg 1983, 70:513-516.

11. Lesser ML, Rosen PP, Kinne DW: Multicentricity and bilaterality in invasive breast carcinoma. Surgery 1982, 91:234-240.

12. du Toit RS, Locker AP, Ellis IO, Elston CW, Nicholson RI, Blamey RW: Invasive lobular carcinomas of the breast-the prognosis of histopathological subtypes. Br J Cancer 1989, 60:605-609.

13. Harris M, Howell A, Chrissohou M, Swindell RI, Hudson M, Sellwood RA: A comparison of the metastatic pattern of infiltrating lobular carcinoma and infiltrating duct carcinoma of the breast. Br J Cancer 1984, 50:23-30.

14. Ashikari R, Huvos AG, Urban JA, Robbins GF: Infiltrating lobular carcinoma of the breast. Cancer 1973, 31:110-116.

15. Mate TP, Carter D, Fischer DB, Hartman PV, McKhann C, Merino M, Prosnitz LR, Weissberg JB: A clinical and histopathologic analysis of the results of conservation surgery and radiation therapy in stage I and II breast carcinoma. Cancer 1986, 58: 1995-2002.

16. Davis RP, Nora PF, Kooy RG, Hines JR: Experience with lobular carcinoma of the breast. Emphasis on recent aspects of management. Arch Surg 1979, 114:485-488.

17. Smith $D B$, Howell $A$, Wagstaff J: Infiltrating lobular carcinoma of the breast: response to endocrine therapy and survival. Eur $J$ Cancer Clin Oncol 1987, 23:979-982.

18. Silverstein MJ, Lewinsky BS, Waisman JR, Gierson ED, Colburn WJ, Senofsky GM, Gamagami P: Infiltrating lobular carcinoma. Is it different from infiltrating duct carcinoma? Cancer 1994, 73:1673-1677.

19. Sastre-Garau X, Jouve M, Asselain B, Vincent-Salomon A, Beuzeboc P, Dorval T, Durand JC, Fourquet A, Pouillart P: Infiltrating lobular carcinoma of the breast. Clinicopathologic analysis of 975 cases with reference to data on conservative therapy and metastatic patterns. Cancer 1996, 77:113-120. 
20. Toikkanen S, Pylkkanen L, Joensuu H: Invasive lobular carcinoma of the breast has better short- and long-term survival than invasive ductal carcinoma. $\mathrm{Br} J$ Cancer 1997, 76:12341240.

21. McGuire WL, De La Garza M, Chamness GC: Evaluation of estrogen receptor assays in human breast cancer tissue. Cancer Res 1977, 37:637-639.

22. Powell B, Garola RE, Chamness GC, McGuire WL: Measurement of progesterone receptor in human breast cancer biopsies. Cancer Res 1979, 39:1678-1682.

23. Dressler LG, Seamer LC, Owens MA, Clark GM, McGuire WL: DNA flow cytometry and prognostic factors in 1331 frozen breast cancer specimens. Cancer 1988, 61:420-427.

24. Clark GM, Wenger CR, Beardslee S, Owens MA, Pounds G, Oldaker T, Vendely P, Pandian MR, Harrington D, McGuire WL: How to integrate steroid hormone receptor, flow cytometric, and other prognostic information in regard to primary breast cancer. Cancer 1993, 71:2157-2162.

25. Clark GM, Dressler LG, Owens MA, Pounds G, Oldaker T, McGuire WL: Prediction of relapse or survival in patients with node-negative breast cancer by DNA flow cytometry. $N$ Engl J Med 1989, 320:627-633.

26. Wenger CR, Beardslee S, Owens MA, Pounds G, Oldaker T, Vendely P, Pandian MR, Harrington D, Clark GM, McGuire WL: DNA ploidy, S-phase, and steroid receptors in more than 127,000 breast cancer patients. Breast Cancer Res Treat 1993, 28:9-20.

27. Ciocca DR, Fujimura FK, Tandon AK, Clark GM, Mark C, LeeChen GJ, Pounds GW, Vendely P, Owens MA, Pandian MR: Correlation of HER-2/neu amplification with expression and with other prognostic factors in 1103 breast cancers. J Natl Cancer Inst 1992, 84:1279-1282.

28. Klijn JG, Berns PM, Schmitz PI, Foekens JA: The clinical significance of epidermal growth factor receptor (EGF-R) in human breast cancer: a review on $\mathbf{5 2 3 2}$ patients. Endocr Rev 1992, 13:3-17.

29. Klijn JG, Berns PM, Bontenbal M, Foekens JA: Growth factors. Clinical implications in breast cancer. Ann N Y Acad Sci 1993, 698:85-101.

30. Allred DC, Clark GM, Elledge R, Fuqua SA, Brown RW, Chamness GC, Osborne CK, McGuire WL: Association of p53 protein expression with tumor cell proliferation rate and clinical outcome in node-negative breast cancer. J Nat/ Cancer Inst 1993, 85:200-206.

31. Henson D, Tarone R: A study of lobular carcinoma of the breast based on the Third National Cancer Survey in The United States of America. Tumori 1979, 65:133-142.

32. Newman W: Lobular carcinoma of the female breast. Report of 73 cases. Ann Surg 1966, 164:305-314.

33. Rosen P: The Pathology of Invasive Breast Carcinoma, 2nd ed. Philadelphia: Lippincott; 1991

34. Diab SG, Elledge RM, Clark GM: Tumor characteristics and clinical outcome of elderly women with breast cancer. J Natl Cancer Inst 2000, 92:550-556.

35. MacGrogan G, Jollet I, Huet S, Sierankowski G, Picot V, Bonichon $F$, Coindre JM: Comparison of quantitative and semiquantitative methods of assessing MIB-1 with the S-phase fraction in breast carcinoma. Mod Pathol 1997, 10:769-776.

36. Lamovec J, Bracko M: Metastatic pattern of infiltrating lobular carcinoma of the breast: an autopsy study. J Surg Oncol 1991, 48:28-33.

37. Harake MD, Maxwell AJ, Sukumar SA: Primary and metastatic lobular carcinoma of the breast. Clin Radiol 2001, 56:621-630.

38. Winston $\mathrm{CB}$, Hadar $\mathrm{O}$, Teitcher JB Caravelli JF Sklarin NT, Panicek DM, Liberman L: Metastatic lobular carcinoma of the breast: patterns of spread in the chest, abdomen, and pelvis on CT. AJR Am J Roentgenol 2000, 175:795-800.

39. Lehr HA, Folpe A, Yaziji H, Kommoss F, Gown AM: Cytokeratin 8 immunostaining pattern and E-cadherin expression distinguish lobular from ductal breast carcinoma. Am J Clin Pathol 2000, 114:190-196.

40. Lamovec J, Zidar A: Association of leptomeningeal carcinomatosis in carcinoma of the breast with infiltrating lobular carcinoma. An autopsy study. Arch Pathol Lab Med 1991, 115: 507-510.

41. Wheeler JE, Enterline HT: Lobular carcinoma of the breast in situ and infiltrating. Pathol Annu 1976, 11:161-188.
42. Fechner RE: Infiltrating lobular carcinoma without lobular carcinoma in situ. Cancer 1972, 29:1539-1545.

43. Helin ML, Helle MJ, Helin HJ, Isola JJ: Proliferative activity and steroid receptors determined by immunohistochemistry in adjacent frozen sections of 102 breast carcinomas. Arch Pathol Lab Med 1989, 113:854-857.

44. Poen JC, Tran L, Juillard G, Selch MT, Giuliano A, Silverstein M Fingerhut A, Lewinsky B, Parker RG: Conservation therapy for invasive lobular carcinoma of the breast. Cancer 1992, 69: 2789-2795.

45. Soslow RA, Carlson DL, Horenstein MG, Osborne MP: A comparison of cell cycle markers in well-differentiated lobular and ductal carcinomas. Breast Cancer Res Treat 2000, 61:161-170.

46. Chassevent $A$, Jourdan ML, Romain S, Descotes F, Colonna M, Martin PM, Bolla M, Spyratos F: S-phase fraction and DNA ploidy in 633 T1T2 breast cancers: a standardized flow cytometric study. Clin Cancer Res 2001, 7:909-917.

47. Domagala W, Markiewski M, Kubiak R, Bartkowiak J, Osborn M: Immunohistochemical profile of invasive lobular carcinoma of the breast: predominantly vimentin and p53 protein negative, cathepsin D and oestrogen receptor positive. Virchows Arch A Pathol Anat Histopathol 1993, 423:497-502.

48. Rosen PP, Lesser ML, Arroyo CD, Cranor M, Borgen P, Norton L: p53 in node-negative breast carcinoma: an immunohistochemical study of epidemiologic risk factors, histologic features, and prognosis. J Clin Oncol 1995, 13:821-830.

49. Rosen PP, Lesser ML, Arroyo CD, Cranor M, Borgen P, Norton L: Immunohistochemical detection of HER2/neu in patients with axillary lymph node negative breast carcinoma. A study of epidemiologic risk factors, histologic features, and prognosis. Cancer 1995, 75:1320-1326.

50. Dixon JM, Anderson TJ, Page DL, Lee D, Duffy SW: Infiltrating lobular carcinoma of the breast. Histopathology 1982, 6:149161.

51. DiCostanzo D, Rosen PP, Gareen I, Franklin S, Lesser M: Prognosis in infiltrating lobular carcinoma. An analysis of 'classical' and variant tumors. Am J Surg Pathol 1990, 14:12-23.

52. Weidner N, Folkman J, Pozza F, Bevilacqua P, Allred EN, Moore $\mathrm{DH}$, Meli S, Gasparini G: Tumor angiogenesis: a new significant and independent prognostic indicator in early-stage breast carcinoma. J Natl Cancer Inst 1992, 84:1875-1887.

53. Fisher ER, Gregorio RM, Fisher B, Redmond C, Vellios F, Sommers SC: The pathology of invasive breast cancer. A syllabus derived from findings of the National Surgical Adjuvant Breast Project (protocol no. 4). Cancer 1975, 36:1-85.

54. Horn PL, Thompson WD: Risk of contralateral breast cancer: associations with factors related to initial breast cancer. $A m \mathrm{~J}$ Epidemiol 1988, 128:309-323.

55. Frost AR, Terahata S, Yeh IT, Siegel RS, Overmoyer B, Silverberg SG: An analysis of prognostic features in infiltrating lobular carcinoma of the breast. Mod Pathol 1995, 8:830-836.

\section{Correspondence}

Richard M Elledge, MD, Breast Care Center at Baylor College of Medicine, 6550 Fannin St., Suite 701, Houston, TX 77030, USA. Tel: +1 (713) 798 1655; fax: +1 713798 8884; e-mail: relledge@breastcenter.tmc.edu 